\title{
COMPETITIVIDADE TERRITORIAL, REGIONALIZAÇÃO E GLOBALIZAÇÃO
}

\author{
Maria Alice Lahorgue ${ }^{1}$
}

\begin{abstract}
Resumo
O artigo aponta que, para tratar do tema da competitividade, regionalização e globalização, deve-se lembrar de que depois dos "30 anos gloriosos", do pós-guerra aos choques do petróleo (1973 e 1979), já se transcorreram mais outros 30 anos. Trata-se, portanto, de um período de 60 anos a serem considerados. A abordagem territorial atual baseia-se na ideia de que o território é a combinação de um espaço cultural, espaço político e espaço econômico. Por fim o artigo apresenta duas discussões importantes: a) o processo democrático de Amartya Sem, que aposta na capacitação das pessoas para participar e poder intervir nas políticas, o que não seria novo em si, pois François Perroux, nos anos 1960, já apontava para isso e b) o movimento Slow Cities Movement, uma rede que nasceu na Itália em 1999 e que tem hoje 140 cidades com no máximo 50 mil habitantes, em vários países. A proposta deste movimento recoloca o que Friedman e Weaver apontaram em 1979, como desenvolvimento endógeno.
\end{abstract}

Palavras-chave: Competitividade. Regionalização. Globalização. Abordagem Territorial. Processo Democrático. Slow Cities Movement

\begin{abstract}
The article points out that to analise the issue of competitiveness, regionalism and globalization, one should remember that after the "30 glorious years" of postwar oil shocks (1973 and 1979), has already passed more than another 30 years. It is therefore a period of 60 years to be considered. The current territorial approach is based on the idea that territory is the combination of a cultural space, political space and economic space. Finally the paper presents two important discussions: a) the democratic process of Amartya Sen, which invests in training people to participate and to be involved in politics, which is not itself new, as François Perroux in the 1960s, had already pointed and b) the Slow Cities Movement, a network that was born in Italy in 1999 and now has 140 cities with a maximum of 50 000 inhabitants in various countries. The purpose of this movement replaces what the Friedman and Weaver had appointed in 1979 as an endogenous development.
\end{abstract}

Keywords: Competitiveness. Regionalization. Globalization. Territorial Approach. Democratic Process. Slow Cities Movement

\footnotetext{
1 Economista. Mestre em Analyse et Aménagement de l'espace - Université de Paris I (Panthéon-Sorbonne Doutora em Sciences Économiques - Université de Paris I (Panthéon-Sorbonne). É professora de economia regional nos programas de pós-graduação em Economia e em Planejamento Urbano e Regional da UFRGS. http://www.ufrgs.br/ppge/ Email: lahorgue@ufrgs.br
} 
A reflexão sobre o tema Planejamento Competitividade Territorial, Regionalização e Globalização leva à natural comparação entre os dois grandes períodos que marcaram os últimos 60 anos. No primeiro período, conhecido na Europa como os 30 gloriosos anos pósSegunda Guerra Mundial, parecia que se caminhava rapidamente para a convergência entre as rendas médias dos países ocidentais. Os 30 anos seguintes foram marcados pelas profundas reestruturações produtivas e sociais, tendo colocado em xeque muitos dos avanços obtidos no período anterior, especialmente o estado de bem-estar social. Dessa forma, esta intervenção traz a discussão desse período de 60 anos, que é um período longo, procurando pinçar as peculiaridades mais marcantes e as reações às tendências passadas desse tempo.

Os 30 gloriosos anos, iniciados no fim da Segunda Guerra Mundial, foram caracterizados pelo rápido crescimento econômico, impulsionado pelos investimentos na reconstrução da Europa, acompanhado de rápida urbanização e industrialização. Esse período findou durante o segundo choque do petróleo, ao apagar das luzes da década de 1970. Nesse segundo choque, ficou claro que, do ponto de vista do consumo energético, eram completamente impossíveis a ampliação e a convergência dos grandes indicadores macroeconômicos em todos os países. Apesar do paulatino reconhecimento da inviabilidade da expansão do consumo energético de acordo com o padrão dos países centrais, e especialmente dos EUA, houve durante largo tempo uma tendência à homogeneização das políticas econômicas nesses anos todos, baseada na ideia fixa de que seria possível a convergência.

Obviamente, algumas vozes dissonantes apareceram, observando que nesse desenvolvimento havia desigualdade crescente entre os países centrais e periféricos. A discussão do desenvolvimento desigual, da divisão internacional do trabalho e do imperialismo acaba chamando mais a atenção do que a discussão do local, que vai acontecer à margem.

Existiu também nessa época uma discussão em relação à replicação desse tipo de mecanismo de dominação da periferia pelo centro dentro dos países. Essa é uma discussão quase permanente ao longo do período dos 30 gloriosos anos. Entre os descontentes, aparecem dois grupos, que perduram na discussão. O primeiro grupo, dos ambientalistas, passa a discutir a inviabilidade da replicação do desenvolvimento a "la Americana", pois não existiriam recursos planetários para tanto. Várias conferências ambientais são realizadas e uma série de pensadores, como René Passet, começa a escrever sobre essa temática.

Os segundo grupo procurou contrastar a ideia de um desenvolvimento funcional ou por cima, onde os países centrais ou as multinacionais tinham todo o poder, com um 
desenvolvimento "por baixo" ou territorial. Nesse grupo, se destacam John Friedmann e Clyde Weaver, que, em 1979, escrevem um livro intitulado Território e Função, no qual chamam a atenção para as possibilidades do que denominam de desenvolvimento territorial.

O desenvolvimento territorial parte da ideia de que o território é a combinação de três espaços: cultural, político e econômico Não há como, em um território, separar uma coisa da outra, pois ele é feito do conjunto desses três tipos de espaço. Ou seja, a história é importante, a estrutura econômica que essa história montou é importante e a organização da sociedade que essa mesma história montou é importante.

John Friedmann e Clyde Weaver, partindo da ideia do território ser a síntese desses espaços e, na realidade, construído na história, fazem uma proposta em que o desenvolvimento deveria dar resposta a determinadas suposições e constatações.

São cinco suposições e constatações que vão desde i) o fato que a maior parte da população do mundo vive em condições de baixo consumo material; ii) produz mais valor de uso que valor de troca e os níveis de consumo são baixos; iii) que uma nação, para se legitimar, deve atender às necessidades de toda a sua população e não somente de uma parte; iv) que a consolidação dessa economia territorial não prescinde nem afasta o desenvolvimento das empresas multinacionais, ou seja, já traz um diálogo à abertura do sistema local para o sistema mundial. Finalmente, v) que o desenvolvimento precisa colocar as funções de produção e distribuição em uma síntese, e esse desenvolvimento precisa ser igualitário.

Os princípios da economia territorial são igualmente cinco e eles nos dizem que:

i) a economia deve aspirar à diversificação;

ii) o desenvolvimento deve ser feito sem prejudicar as gerações futuras, ou seja, mantendo os princípios da conservação;

iii) o desenvolvimento deve animar a expansão dos mercados regionais e interregionais, ou seja, doméstico;

iv) deve basear-se no autofinanciamento. $\mathrm{Na}$ época, havia uma quantidade muito grande de recursos livres. Uma parte importante do desenvolvimento do Terceiro Mundo estava sendo feito em cima de financiamento, sendo que um dia os empréstimos deveriam ser pagos. O princípio do autofinanciamento era um lembrete de que um dia esses empréstimos deveriam ser pagos. Essa questão do autofinanciamento é importante hoje, mas na época era mais importante ainda; 
v) o desenvolvimento deve promover o aprendizado social, ou seja, a organização da sociedade tem que se desenvolver junto com o próprio desenvolvimento e crescimento da economia.

Dessa forma, vem uma constatação óbvia. Como nos lugares menores é mais fácil encontrar consensos e descobrir capital social, a proposta de Friedmann e Weaver estava baseada em localidades de menor porte. Na época, essa proposta foi considerada extremamente radical, pois buscava alterar a lógica das políticas de desenvolvimento. Tínhamos uma parte importante que seguia o mesmo receituário, e essas propostas de John Friedmann e Clyde Weaver passam a ser mediadas por uma posição que irá reconhecer a importância do local e sua história. Essa abordagem trabalha com a região e com o local, admitindo e reconhecendo a integração funcional.

Na realidade, nos anos 1980, essa posição intermediária é reforçada, por exemplo, pela descoberta dos distritos industriais italianos, que mostraram que um local especializado podia trazer bem-estar e riqueza para sua população em um mercado globalizado, produzindo para o mundo inteiro. Essa junção de uma integração relativamente funcional com a região acontece nos anos 1980.

Os contornos dos 30 anos seguintes aos "gloriosos" conhece-se muito bem: mudança de paradigmas, fim do protecionismo, globalização, importância do capitalismo financeiro, desmaterialização da produção da riqueza, entre outros elementos. Essa desmaterialização vai ser entendida como desindustrializarão em alguns cantos, mas ela é sólida hoje, já que se calcula que $70 \%$ da riqueza mundial é imaterial.

No início desse segundo período de 30 anos, parecia que o novo paradigma informacional, com as tecnologias de informação e comunicação, poderia realizar aquilo que o crescimento continuado do período anterior não havia conseguido, que era atomizar a produção e conseguir um desenvolvimento mais harmônico em termos globais.

Durante certo tempo, parecia ser possível inserir os países menos desenvolvidos nessa formatação do mercado global, com novas tecnologias, etc. Mas, convencionou-se chamar esta possível inserção de competitividade espúria, ou seja, ela simplesmente estava baseada em baixos salários e relações de trabalho flexíveis com alta informalidade. Em seguida, verificou-se que essa estratégia de inserção baseada em competitividade espúria tinha seus limites, o da própria concorrência entre os países menos desenvolvidos. Por exemplo, se analisarmos o caso dos discos rígidos produzidos, vê-se que uma parte é produzida em 
Taiwan, a parte da inteligência, mas que a produção e manufatura são distribuídas na região em países de menor salário.

Isso é um contínuo que começa a ficar bem claro nos anos 1990. Portanto, ficou para países como o Brasil, países médios que querem chegar ao alto, a inserção competitiva por baixo salário com limites muito retraídos. Ficou claro que, sem aumento da produtividade, não havia como ter uma inserção positiva nesse novo mundo. Surgem a modernização e a inovação como sustentáculos da competitividade no longo prazo.

Nos anos 1980, quando se têm novos ambientes da economia do conhecimento, da informação, etc., se verificou que esses ambientes inovadores precisavam da proximidade das infraestruturas de ciência e tecnologia e, principalmente, da formação de pessoas. Isso trouxe vantagem para as cidades e regiões que possuem esse tipo de infraestrutura, com uma nova condição de centralização. Parecia que as Tecnologias da Informação e Comunicação (TIC) poderiam se espalhar e as pessoas poderiam trabalhar e produzir em qualquer lugar do mundo, mas se percebeu que não, pois para conseguir fazer isso, tem que ter inovação e, para ter inovação, é preciso estar próximo das fontes de conhecimento.

Em lugares como o Brasil, essas fontes de conhecimento estão majoritariamente nas capitais dos estados. Foi calculado pelo CEDEPLAR (UFMG) o índice de Gini para a produção de conhecimento. O menor índice de concentração é São Paulo, com cerca de 0,98. Em vários estados, o índice é 1, ou seja, todo o conhecimento é produzido em um município, o município capital. Isso é um novo incentivo à centralização.

A seguinte constatação desse período é que as metrópoles, sobretudo as metrópoles do Terceiro Mundo, que haviam sofrido com o inchaço da migração rural-urbana na época de 1960-70 e parte dos anos 1980, e que pareciam fadadas a se acabar, por deseconomias externas, congestionamentos, entre outros, se transformam em atores-chave da nova economia. Descobre-se, primeiro, que elas são o lócus histórico da produção do conhecimento e o mundo inteiro redescobre a metrópole e, no mundo inteiro, ela renasce, ou seja, se encontra mais outra condição de recentralização. A ideia renovada de convergência acaba sendo diminuída na sua importância na própria evolução dos fatos.

As políticas passam a reconhecer, pelo menos no discurso, que a questão da sociedade é importante, a questão dos atores é importante, que a organização da sociedade é importante. Entretanto, no receituário do desenvolvimento, encontramos padrões de anos anteriores.

Nos anos 1970, os municípios construíam áreas industriais e davam incentivos fiscais para as empresas se localizarem, pois elas seriam o "passaporte" para o desenvolvimento. 
Hoje, os municípios estão atrás de parques tecnológicos. Qual é a diferença? Custa-se a ver qual a diferença entre um e outro.

Essa questão da imitação é constante, pode-se ver isso ao longo da história mundial. Obviamente, isso não significa que uma parte da imitação não seja importante. É importante saber o que os outros estão fazendo, mas ao mesmo tempo é importante um olhar para dentro, um olhar crítico no sentido de entender as potencialidades realmente existentes e identificar as coisas que são meros desejos, que provavelmente não terminarão bem.

\section{A QUESTÃo DA REGIONALIZAÇÃo E GLOBALIZAÇÃo}

Há uma necessidade de pensar a globalização do ponto de vista regional. Antes dos anos 1990, antes da rodada do Uruguai, havia um mundo de estratégias multinacionais, multidomésticas. Isso significa que se uma determinada multinacional quisesse vender seu produto em um determinado país, ela teria que montar sua planta produtiva naquele país e cada planta teria o tamanho do mercado respectivo.

Quando tiramos as barreiras tarifárias, há uma concentração de relocalizações nos países que têm as melhores condições de proporcionar principalmente mercado e economias externas. Que economias externas são essas? Logística, formação de pessoal, condições de inovação, etc. Tomando-se o que aconteceu no Mercosul, depois de 1992, quando foi criado, pode-se observar que várias plantas se mudaram da Argentina para o Brasil. O que fica na Argentina é o fornecedor dessa planta principal, que irá vender para todos os países do grupo. Pode haver uma situação em que um determinado país vire simplesmente espaço de consumo, onde não se produz nada e simplesmente se consome, como parece ser o caso do Paraguai.

Ora, como contrarrestar isso, que parece, pela lógica, extremamente forte? Isso se faz com o pensamento de estratégia nacional. Portanto, o planejamento nacional, com o conjunto das regiões, é o caminho para se antever e para controlar a evolução das estratégias globais. Por que antever? Porque se vive olhando o passado, fazendo pouca prospectiva. Com muita dificuldade, consegue-se alongar uma curva ou analisar as transformações possíveis das cadeias de valor. Esse antever, para controlar e tomar decisões em relação a estratégias globais, é o planejamento racional que tem uma função.

A repartição territorial das políticas nacionais deve ser construída com diálogo que vai se dar na nação, na região, no município ou no local. No final, as coisas acontecem no local. Portanto, esse diálogo tem que acontecer; um diálogo em um país que tem mais de 5000 municípios é extremamente difícil de fazer. Mas, o diálogo direto é necessário, pois fazer o 
diálogo só com os estados não é suficiente. Tem-se no Brasil uma multitude de visões regionais que são gerenciadas no âmbito de cada estado federado, mas esse meio moderador, que é a região, não pode nunca ocultar as diferenças internas, pois elas vão se dar entre os municípios, entre as localidades. O diálogo com um ente privilegiado que é a região, mas, esse ente não pode ocultar as diferenças intra-região, e isso é importante porque fica cada vez mais claro que a política "chapada", que não vê nuances, não funciona para todo mundo.

Assim, como se teve reações lá atrás, temos outras reações contemporâneas. Talvez elas possam dar algumas pistas para a elaboração de políticas efetivamente territorializadas, não somente no discurso.

Passo a tratar de duas questões. A primeira delas é a abordagem pelas capacitações do Amartya Sen, que traz à reflexão uma pergunta muito simples. Ele diz que todo pesquisador e todo planejador desejam o bem da comunidade, mas a grande questão é quem decide o que é bom?

Esse processo democrático que Amartya Sen traz, ele o traz junto com uma discussão da capacitação das pessoas para participar disso, para poder intervir nas políticas que as afetarão diretamente. Esse pensamento parece novo, mas gostaria de lembrar que o francês François Perroux, nos anos 1960, colocava exatamente isso, que o desenvolvimento podia partir de um ponto, mas o seu desdobramento necessitaria de uma organização consciente no sentido de fazer com que os frutos desse desenvolvimento se distribuíssem de forma igualitária e, ao mesmo tempo, ele lembrava que somente a ação do governo não era suficiente, pois era necessário ter uma população preparada para isso.

A primeira pista é trazer para a discussão os atores, que são importantes e não podem ser esquecidos. Parece simples, mas muitas vezes nossas políticas passam por cima dos atores.

O próximo ponto é o movimento Slow Cities Movement, uma rede que nasceu na Itália, em 1999. Essa rede tem hoje 140 cidades de no máximo 50 mil habitantes, no mundo inteiro, na Ásia, na Austrália, na França, em Portugal, na Itália, onde nasceu, e nos Estados Unidos.

O movimento está ligado às mesmas pessoas que criaram o Slow Food, surgido na Itália no momento em que anunciaram que iriam colocar um McDonald's perto da Praça da Espanha, em Roma. A partir disso, teve um movimento por parte dos restaurantes e gastrônomos para preservar a gastronomia e sua ligação com a terra. Assim se criou o movimento Slow Food.

Para um município aderir ao Slow Cities Movement, deve atender a uma carta com 50 critérios. As Slow Cities "são lugares onde os cidadãos e os líderes locais prestam atenção na 
história local e utilizam o contexto local e descritivo para desenvolvê-los de forma melhor e mais sustentável" (site do movimento).

Quando se observa a Carta do Slow Cities, vê-se que aquilo que Friedmann e Weaver colocavam em 1979, como desenvolvimento endógeno, é o que está acontecendo agora. O mais interessante é que a literatura sobre esse movimento de cidades lentas não cita Friedman e Weaver. De toda forma, parece existir uma outra grande ideia da humanidade, aquela de fazer um outro tipo de desenvolvimento, de buscar alternativas para o desenvolvimento hegemônico.

A terceira pista é que as condições locais constituem o caminho crítico das alternativas de desenvolvimento. Essas condições locais devem ser vistas do ponto de vista crítico de duas formas: do que realmente é potencial e do que realmente são coisas que não vão acontecer.

A questão do desenvolvimento contemporâneo traz a necessidade de se repensar alguns pontos.

Efetivamente, aquelas cidades que se sentem como se fossem uma ilha não o são, elas estão no continente; elas não precisam ter a percepção de serem remotas no sentido que nada chega ali, que a modernidade não chega. Mas, que modernidade é essa? Essa é uma questão em aberto e que nós, como estudiosos da área, podemos, e devemos, dar respostas, seja estudando ou praticando. 